\title{
Analysis of the economic performance of municipal Children's Hospitals in Shanghai: a study on the impacts of policy changes in healthcare service prices
}

\author{
Yuanyuan An ${ }^{1 \#}$, Miao Wang ${ }^{2 \#}$, Xiaoyu Wu ${ }^{1}$, Linan Wang ${ }^{3,4}$, Kunkun Zhang ${ }^{1}$ \\ ${ }^{1}$ Department of Finance, Shanghai Children's Hospital, Shanghai Jiao Tong University, Shanghai, China; ${ }^{2}$ Medical Department, Shanghai Children's \\ Hospital, Shanghai Jiao Tong University, Shanghai, China; ${ }^{3}$ School of Public Economics and Administration, Shanghai University of Finance and \\ Economics, Shanghai, China; ${ }^{4}$ Department of Health Policy Research, Shanghai Health Development Research Center, Shanghai, China \\ Contributions: (I) Conception and design: K Zhang; (II) Administrative support: Y An; (III) Provision of study materials or patients: L Wang; (IV) \\ Collection and assembly of data: X Wu; (V) Data analysis and interpretation: Y An; (VI) Manuscript writing: All authors; (VII) Final approval of \\ manuscript: All authors. \\ \#These authors contributed equally to this work. \\ Correspondence to: Kunkun Zhang. Department of Finance, Shanghai Children's Hospital, Shanghai Jiao Tong University, 355 Luding Road, Putuo \\ District, Shanghai 200062, China. Email: zhangkunkun@shchildren.com.cn.
}

Background: Since the Shanghai municipal government launched the latest round of medical service price reform in 2015, public hospitals have gradually abolished the prices of drugs and consumables, and increased the prices of healthcare services to properly reflect the labor value of medical workers. Under the price reform policy, we should pay more attention to the operation of children's hospitals.

Methods: Literature review: we conducted a systematic review of the economic performance of municipal children's hospitals in Shanghai and the relevant policies on healthcare service price reform. Data analysis: we use the relevant economic performance statistics of municipal children's hospitals and comprehensive hospitals in Shanghai during 2012-2018 to analyze the impacts of healthcare service price reform on children's hospitals based on time series and hospital type. Expert interview: to expand upon the data analysis, we interviewed some experts to discuss solutions for addressing the difficulties in developing municipal children's hospitals.

Results: Since the pricing reform, the revenue composition of children's hospitals has dramatically improved. However, the slightly insufficient potential of their business growth exacerbates their losses and hurts their economic performance.

Conclusions: In the future, municipal children's hospitals should strengthen their internal management, sharpen their orientation tuning, improve their healthcare service quality, and improve their operational efficiency. Meanwhile, the government needs to provide relevant policy support and help children's hospitals in their efforts to further improve and grow. Part of the policy recommendations of this study have been included in the next round of important measures for Shanghai's medical reform and planning.

Keywords: Children's hospitals; price reform policies; children's health

Submitted May 18, 2020. Accepted for publication Nov 20, 2020.

doi: 10.21037/atm-20-6863

View this article at: http://dx.doi.org/10.21037/atm-20-6863

\section{Introduction}

Healthcare services of public hospitals refer to the provision of services such as diagnosis and accommodation, inspection and laboratory tests, surgical anesthesia, and drug consumables for the purpose of caring for life and diagnosis and treatment of diseases. In order to reflect the public welfare, the price of healthcare services in public hospitals is subject to government control, and the overall price of 
healthcare services is lower than the cost.

In recent years, the prices of medicines and consumables have risen year by year. Patients generally report that the cost of medical treatment is high and the medical insurance department is under pressure to pay. However, the value of doctors' labor services has not been reflected accordingly, which has led to intensified conflicts between doctors and patients. In order to control the growth of medical expenses, optimize the medical structure, and better reflect the labor value of medical staff, the government has implemented a new round of healthcare service price reforms to guide hospitals to optimize the medical service structure, improve operational capabilities, and at the same time encourage doctors to improve their skills and curb Use medicines and consumables reasonably.

Healthcare service price reform has gradually become a key action area for public hospital reform owing to the enactment of such policies as the "Notice on the Directives of the Healthcare Service Price Adjustment for the Public Hospitals Subject to Comprehensive Reform" \{National Development and Reform Commission (NDRC) [2015] No. 1830\}, the "Notice on the Issuance and Implementation of the Directives of the Healthcare Service Price Adjustment Reform" \{NDRC [2016] No. 1431\}, and the relevant national policies on healthcare system reform during the period of the 12th Five-Year Plan.

During the past few years, each province and municipality directly under the central government has initiated its own local healthcare service adjustments. The Shanghai Municipal Development and Reform Commission (SMDRC) issued its "2015 Key Points for Deepening the Healthcare System Reform in Shanghai" [SMDRC [2015] No. 2\}. The Key Points focus on improving the government compensation mechanism for public hospitals and improving the medical service pricing. The price adjustments during the recent reform have gotten the attention of the government and all circles of society.

Before the new round of medical reform, there are three types of compensation channels: financial subsidy income, income from medical service items, and income from drugs and consumables. Among them, the mark-up income of medicines and consumables refers to the mark-up income that hospitals obtain by selling them to patients after adding a certain percentage to the wholesale price of medicines and consumables in accordance with the national price policy. The reform of public hospitals requires the improvement of the compensation mechanism for public hospitals, from three channels to two channels. At the end of 2017, the drug addition of public hospitals nationwide was canceled, and the addition of consumables was also required to be gradually canceled. Correspondingly, it provides the space for price adjustment of medical services.

Since Shanghai started its latest round of healthcare service price reform, municipal hospitals in the city have adjusted their healthcare service prices in phases. Public hospitals have canceled the medicine price addition and consumable price addition and ended the practice of using medicine price addition to subsidize healthcare service deficits. The compensation mechanisms for municipal public hospitals have therefore changed. Based on a comparative analysis on the healthcare service prices in Beijing, Shanghai, Guangzhou, Shenzhen, and other firsttier cities (1), Shanghai is gradually increasing the prices of some healthcare services and compensating hospitals via payments form the healthcare security fund. The objectives are to properly reflect the value of the labor of healthcare workers (2,3), respect healthcare workers' efforts, and advance the price reform smoothly and orderly.

The price adjustment of healthcare services is advancing simultaneously, and the impact of policies on different hospitals is different. Children's hospitals have worse economic performance than general hospitals. Specifically, firstly, children lack the ability to protect themselves. They usually have a rapid onset, rapid changes in their illness, and high medical demands. However, the overall medical resources of children's hospitals are relatively scarce and require attention; secondly, young children will not express their illness or express themselves. The ability of medical staff is weaker, and medical staff need to pay more labor costs than adult hospitals when seeing a doctor. Therefore, the income structure of children's hospitals is different from that of adult hospitals.

A comparison of the National Health Service Price Items Standard (2012 Edition) and the new medical service standards after the price reform policy indicates that the latest round of medical price reform includes some extra price increases in the healthcare services for children. The prices of over 80 kinds of diagnostic and treatment services for children below six years old, including puncturing, endoscopic biopsy sampling, and injection, have been raised proportionally to compensate children's hospitals for the extra medical service costs entailed in these treatments. These measures aim to relieve the economic pressure on their daily operations and improve their capacity to provide healthcare services to children.

The implementation of the price adjustment policies has 
had major effects on the economic performance of children's hospitals. On the one hand, the revenue composition of municipal children's hospitals has seen some optimization, the share of medicine revenue has declined, and the service efficiency has improved. However, compared with the municipal general hospitals, the municipal children's hospitals face some special difficulties in their economic performance and growth, and the medical service price reform fails to achieve the original targets (4).

China is making a national effort to provide all-around and life-long healthcare for all social groups. Against such a background, this paper compares the revenue and cost structures of some municipal children's hospitals in Shanghai before and after the medical service price reform to analyze the price reform policies' impacts on the economic performance of these hospitals. It aims to explore approaches to improve the economic performance of children's hospitals, so as to boost the sustainable development of municipal children's hospitals under the policy of medical service price adjustment. We present the following article in accordance with the PRISMA reporting checklist (available at http://dx.doi.org/10.21037/ atm-20-6863).

\section{Methods}

\section{Literature review}

By searching such online journal article databases as the China Industry Knowledge Platform (www.cnki.net), the VIP Paper Check System (www.cquip.com), and Wanfang Data (www.wanfangdata.com.cn) and government websites, we systematically collected academic articles and government policy documents on the economic operations of municipal children's hospitals and the healthcare service price reform.

\section{Data analysis}

The authors collected statistics on the economic performance of municipal children's hospitals and general hospitals in Shanghai during 2012-2018 and assessed the price reform policy's impacts on the economic performance of children's hospitals through comparative analysis.

\section{Expert interview}

The authors conducted face-to-face interviews with price administration experts, hospital management experts, and pediatricians and discussed with them the operational difficulties that children's hospitals face and the possible solutions to address them.

\section{Study analysis}

\section{Data source}

The data source is the revenue and expenditure statistics published by municipal hospitals in Shanghai. In this study, three municipal children's hospitals were selected as the study group, while 11 municipal general hospitals were chosen as the reference group.

\section{Data analysis}

The data were collected and processed with Excel, then analyzed in two dimensions: time series and hospital type. The analysis covers the hospital healthcare revenue, costs, balances, and changes in composition to assess the impacts of the healthcare price reform on children's hospitals. Because the healthcare service price reform started in December 2015 in Shanghai, the reform hardly had any impact on the hospitals' economic performance in 2015. In the analysis, we defined $2012-2015$ as the preadjustment period and 2016-2018 as the postadjustment period and compared the data of the two periods.

\section{Results}

\section{Changes in the revenue of children's hospitals}

The healthcare revenue of the municipal children's hospitals has grown steadily, with an average year-on-year growth of $11.70 \%$ during 2013-2018. Among the different items, the average year-on-year growth rates of revenues from healthcare services, checkup and testing, and medical materials are all higher than the overall growth rates, at $13.46 \%, 16.80 \%$, and $13.88 \%$, respectively. In contrast, the average year-on-year growth rate of medicine revenue is lower than the overall level, at only $6.58 \%$ (see Table 1).

A comparison of the data of the preadjustment period and the data of the postadjustment period indicates that after the price adjustment, the revenue growth rate declines, yet the revenue composition improves. Before the price adjustment, the average year-on-year growth of total healthcare revenue is $12.35 \%$; in particular, the average year-on-year growth rates of checkup and test revenue and medical material revenue are, respectively, $15.22 \%$ and $17.19 \%$, which are 2.87 and 4.84 percentage points higher than the growth rate of total revenue. The average year-on- 


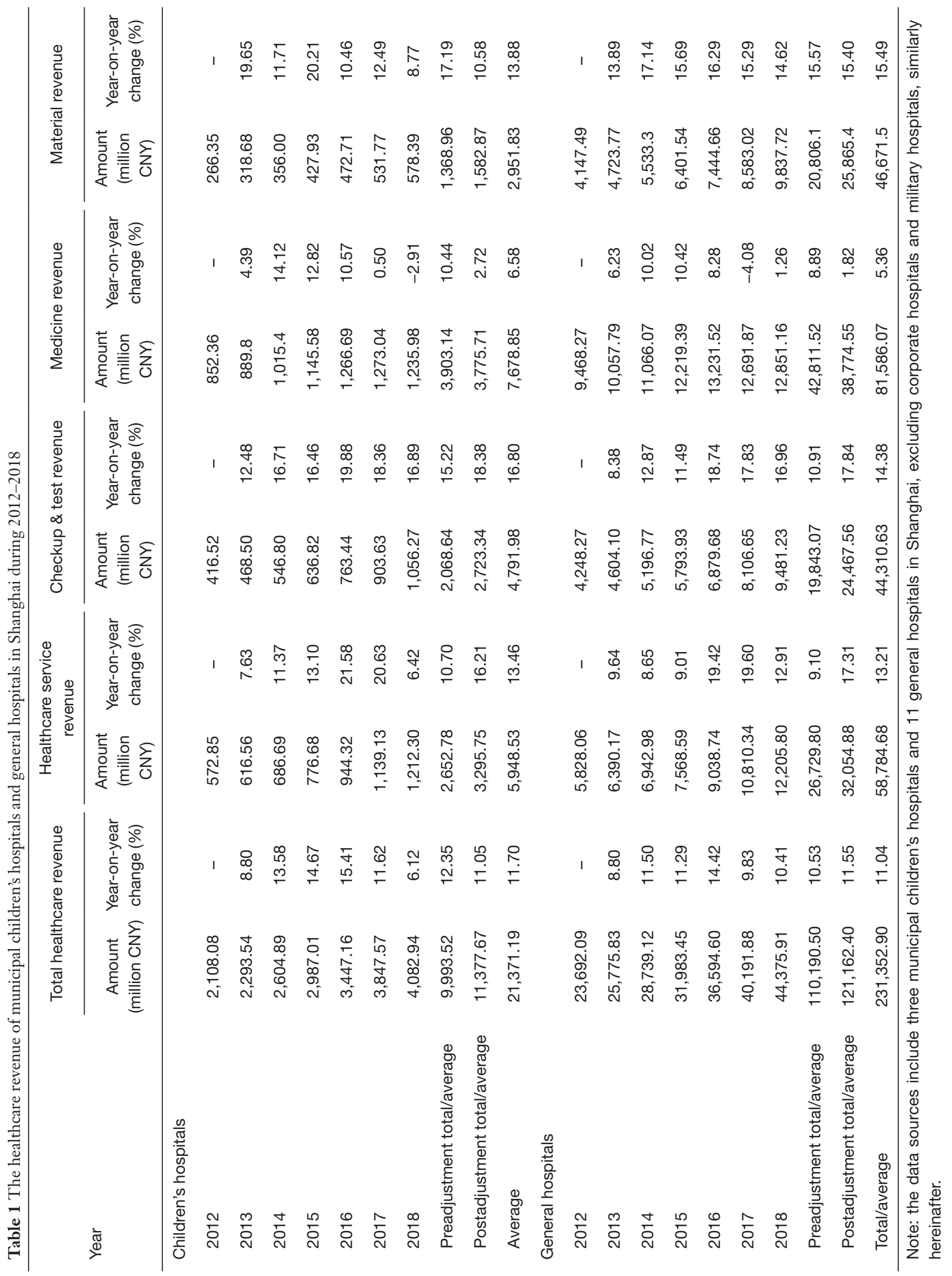


year growth rates of medical service revenue and medicine revenue are, respectively, $10.70 \%$ and $10.44 \%$, which are 1.64 and 1.90 percentage points lower than the growth rate of total revenue. In the years after the price adjustment, the average year-on-year growth rate of healthcare revenue is $11.05 \%$. The average year-on-year growth rates of medical service revenue and checkup and testing revenue are, respectively, $16.21 \%$ and $18.38 \%$, which are 5.17 and 7.33 percentage points higher than the average growth rate of total revenue. In contrast, the medicine revenue and medical material revenue grow by $2.72 \%$ and $10.58 \%$ per year, which are 8.33 and 0.47 percentage points lower than the total revenue growth rate (see Table 1). Thus, the healthcare business revenue of children's hospitals has experienced slower revenue growth after the price adjustments, and their revenue composition has seen some improvement. The medical service revenue and the checkup and testing revenue have rapidly grown, while the growth rates of medicine revenue and material revenue have slowed. The medicine revenue even declines in 2018, while the children's hospitals' dependency on medicine and medical material revenue have gradually lessened.

Compared with general hospitals, after the price adjustments, children's hospitals have slower overall business revenue growth. In particular, their healthcare service revenue and material revenue growth rates are lower than those of general hospitals, while their checkup and testing revenue and medicine revenue grow faster than those of general hospitals. A comparison on the preadjustment and postadjustment trends of revenue indicates that the growth rate changes in the healthcare service revenue and checkup and testing revenue of children's hospitals due to the price adjustment are smaller than those of general hospitals. At the same time, due to the adjustment, their growth rates of medicine revenue and material revenue slow down more, indicating the high effectiveness of the price adjustments' controlling effect. In summary, children's hospitals are more sensitive to the price reform policy, yet their business growth potential seems to be slightly too low (see Table 1).

\section{Analysis of the revenue composition of children's hospitals}

Before the price adjustment, the children's hospitals' revenue composition did not change much. After the price adjustment, the revenue composition has dramatically improved. Among the different sources of revenue, before the price adjustments, the share of medical service revenue is declining; after the price adjustments, it increases, and the most significant increase occurs during 2016-2017; in 2018, the increase stabilizes. Before the price adjustment, the checkup and testing revenue's share only increase slightly; after the adjustment, the positive change becomes significant, and the greatest positive change comes in 2018 . Before the price adjustment, the share of medicine revenue out of the total revenue remains more or less the same; after the price adjustment, the share change dramatically shrinks. The share of medical material revenue slightly fluctuates before and after the adjustment, and the changes are insignificant (see Table 2).

The overall trends of revenue composition changes in children's hospitals are consistent with those in general hospitals, yet the shares of healthcare service revenue and checkup and testing revenue are higher than those in general hospitals, while the share of material revenue is dramatically lower than that in general hospitals. Compared with general hospitals, the children's hospitals receive a larger share of their revenue from healthcare services and hence have better revenue composition (see Table 2).

\section{Healthcare cost changes in children's hospitals}

The operational costs of the municipal children's hospitals have been growing each year, and the average year-on-year growth rate during $2013-2018$ is $11.76 \%$. Specifically, the labor costs and medical material costs increase faster than the total operational revenue, and their average year-onyear growth rates are, respectively, $16.02 \%$ and $17.31 \%$. In contrast, medicine cost has an average year-on-year growth rate of $8.63 \%$, slower than the total operational revenue growth rate (see Table 3).

After the price adjustment, the costs of healthcare services see an average increase of $1.2 \%$ from the levels before the price adjustment. Among the different cost items, the year-on-year average growth rates of the labor costs and material costs are, respectively, $16.38 \%$ and $17.32 \%$, which are 4.02 and 4.96 percentage points higher than the growth of the medical service cost. Moreover, the growth rates of labor cost and material costs are, respectively, $0.73 \%$ and $0.02 \%$ higher than the average year-on-year annual growth rate before the price adjustment. The annual growth rate of medicine cost is $6.56 \%$, which is 5.8 percentage points lower than the annual growth rate of the medical service cost and 4.15 percentage points lower than the average annual growth rate of medicine costs before the price adjustment (see Table 3). The above data indicate that after the enactment of the price adjustment policy, the increase in 
Table 2 Revenue composition of municipal children's hospitals and general hospitals in Shanghai during 2012-2018

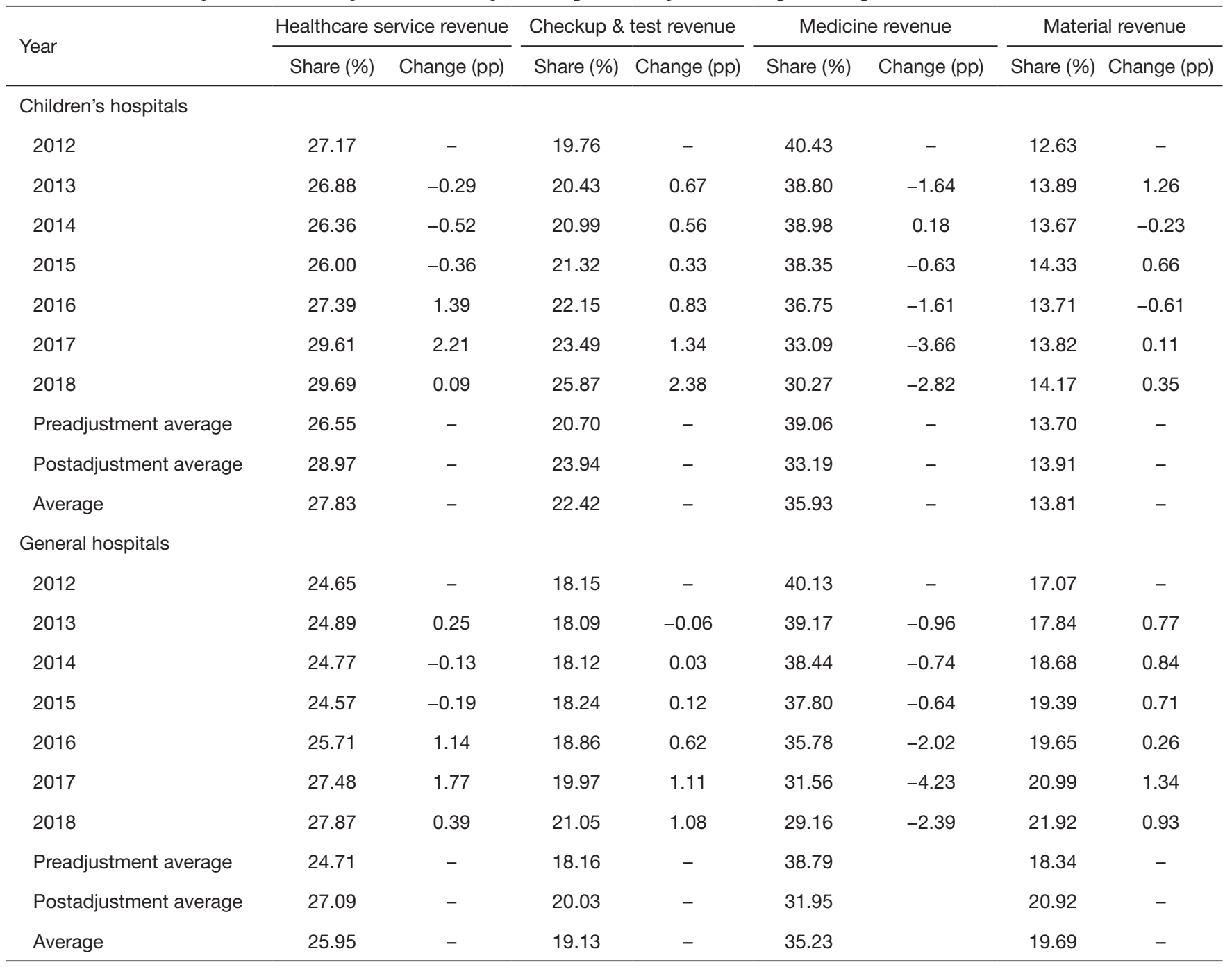

medicine cost dramatically slows. Labor cost and material costs keep more or less the same growth rates as before the price adjustment.

After the price adjustments, the overall healthcare cost growth of children's hospitals is slower than those of general hospitals. In particular, children's hospitals' medicine cost increases significantly more slowly than general hospitals', yet their labor cost increase is faster. As for the average year-on-year growth rate before and after the price adjustment, the growth rate changes in total healthcare costs of children's hospitals is smaller than that of general hospitals. In particular, in children's hospitals, the postadjustment average annual increase in medicine costs is 4.15 percentage points lower than the preadjustment level; in contrast, in general hospitals, it is 4 percentage points higher than the preadjustment level. Moreover, the growth rates of labor costs and material costs in children's hospitals are lower than those of general hospitals both before and after the price adjustments. Children's hospitals successfully slow the growth rate of their medicine costs after the price adjustment, but they need to do more to control the growth rate of their material costs (see Table 3).

\section{Analysis of the changes in the cost composition of children's bospitals}

Before the price adjustment, the cost composition holds fairly steady; after the price adjustment, the cost 


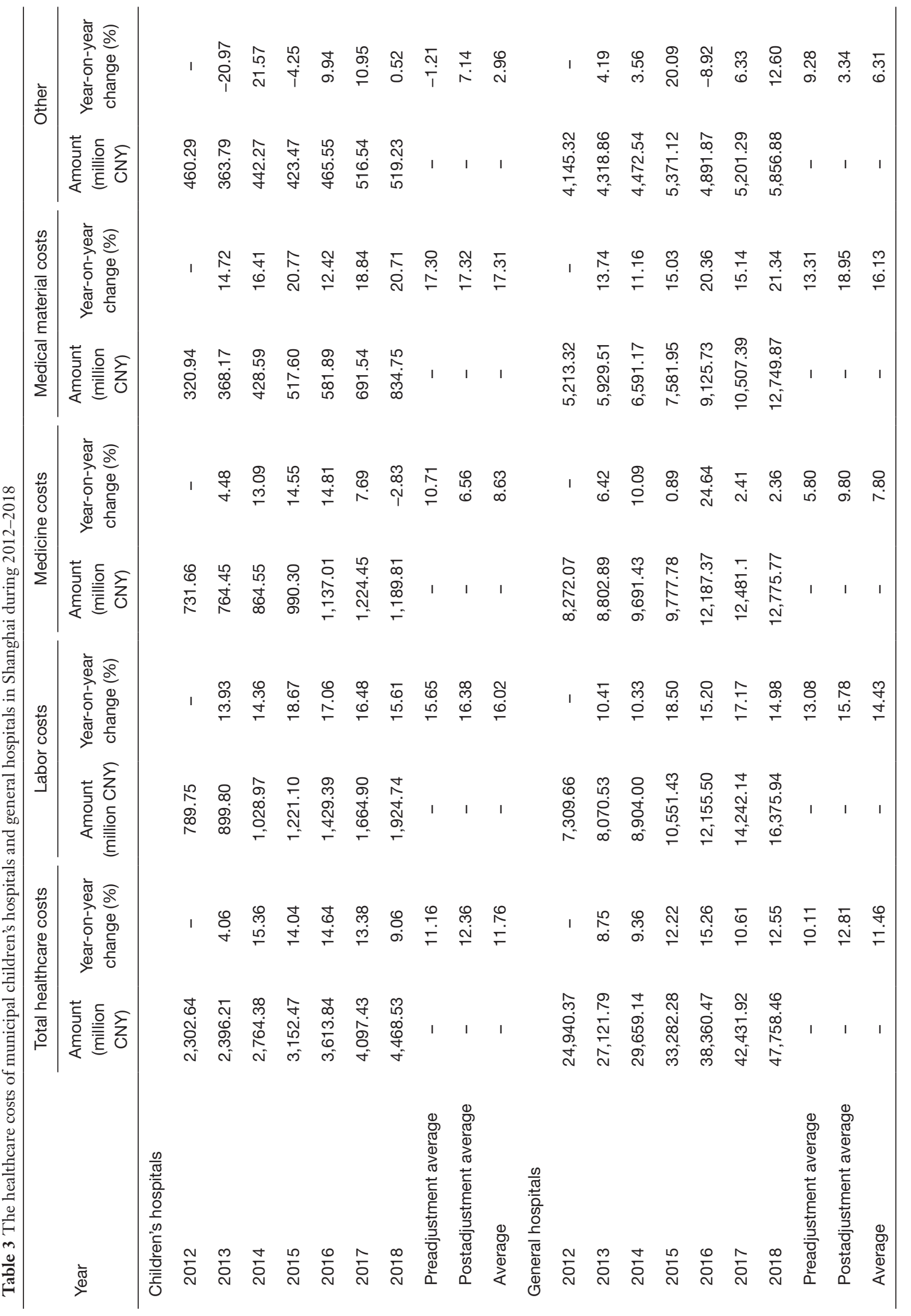


Table 4 The healthcare cost composition of municipal children's hospitals and general hospitals in Shanghai during 2012-2018

\begin{tabular}{|c|c|c|c|c|c|c|c|c|}
\hline Year & \multicolumn{2}{|c|}{ Labor cost } & \multicolumn{2}{|c|}{ Medicine costs } & \multicolumn{2}{|c|}{ Medical material costs } & \multicolumn{2}{|c|}{ Other } \\
\hline \multicolumn{9}{|l|}{ Children's hospitals } \\
\hline 2012 & 34.30 & - & 31.77 & - & 13.94 & - & 19.99 & - \\
\hline 2013 & 37.55 & 3.25 & 31.90 & 0.13 & 15.36 & 1.43 & 15.18 & -4.81 \\
\hline 2015 & 38.73 & 1.51 & 31.41 & 0.14 & 16.42 & 0.91 & 13.43 & -2.57 \\
\hline 2016 & 39.55 & 0.82 & 31.46 & 0.05 & 16.10 & -0.32 & 12.88 & -0.55 \\
\hline 2017 & 40.63 & 1.08 & 29.88 & -1.58 & 16.88 & 0.78 & 12.61 & -0.28 \\
\hline 2018 & 43.07 & 2.44 & 26.63 & -3.26 & 18.68 & 1.80 & 11.62 & -0.99 \\
\hline Average & 39.30 & - & 30.28 & - & 16.42 & - & 14.00 & - \\
\hline \multicolumn{9}{|l|}{ General hospitals } \\
\hline 2012 & 29.31 & - & 33.17 & - & 20.90 & - & 16.62 & - \\
\hline 2013 & 29.76 & 0.45 & 32.46 & -0.71 & 21.86 & 0.96 & 15.92 & -0.70 \\
\hline 2014 & 30.02 & 0.26 & 32.68 & 0.22 & 22.22 & 0.36 & 15.08 & -0.84 \\
\hline 2015 & 31.70 & 1.68 & 29.38 & -3.30 & 22.78 & 0.56 & 16.14 & 1.06 \\
\hline 2016 & 31.69 & -0.02 & 31.77 & 2.39 & 23.79 & 1.01 & 12.75 & -3.39 \\
\hline 2017 & 33.56 & 1.88 & 29.41 & -2.36 & 24.76 & 0.97 & 12.26 & -0.49 \\
\hline
\end{tabular}

composition undergoes some changes. Since the start of the price adjustment policy, hospitals have constantly improved their management of the rationality of medicine prescription, and hence the share of medicine costs has been gradually shrinking. Meanwhile, the shares of labor costs and material costs have been expanding. Since the implementation of the price adjustment, the share of labor costs had increased from $39.55 \%$ in 2016 to $43.07 \%$ in 2018, a growth of 3.52 percentage points. The share of material costs rose from $16.01 \%$ in 2016 to $18.68 \%$ in 2018 , a growth of 2.58 percentage points (see Table 4).

After the price adjustments, the direction of the cost composition changes in children's hospitals is in line with that in general hospitals. In terms of the shares of different costs, both the share and the share increase of the labor costs in children's hospitals are higher than those in general hospitals. In contrast, their share and their share increase in material costs are both lower than those in general hospitals. Such differences are in line with the higher service content of children's hospitals.

\section{Changes in children's bospitals' balance of financial revenue and expenditures}

Children's hospitals' balances of financial revenue and expenditures are negative both before and after the price adjustments, indicating that their healthcare revenue is unable to cover their healthcare service costs. After the price 
Table 5 The balance of financial revenue and expenditures of municipal children's hospitals and general hospitals in Shanghai during 2012-2018

\begin{tabular}{lccc}
\hline Year & Healthcare revenue (million CNY) & Healthcare costs (million CNY) & Balance (\%) \\
\hline Children's hospitals & & & -9.23 \\
2012 & $2,108.08$ & $2,302.64$ & -4.48 \\
2013 & $2,293.54$ & $2,396.21$ & -6.12 \\
2014 & $2,604.89$ & $2,764.38$ & -5.54 \\
2015 & $2,987.01$ & $3,152.47$ & -4.84 \\
2016 & $3,447.16$ & $3,613.84$ & -6.49 \\
2017 & $3,847.57$ & $4,097.43$ & -9.44 \\
2018 & $4,082.94$ & $4,468.53$ & -5.27 \\
General hospitals & & & -5.22 \\
2012 & $23,692.09$ & $24,940.37$ & -3.20 \\
2013 & $25,775.83$ & $27,121.79$ & -4.06 \\
2014 & $28,739.12$ & $29,659.14$ & -4.83 \\
2015 & $31,983.45$ & $33,282.28$ & -5.57 \\
2016 & $36,594.60$ & $38,360.47$ & -7.62 \\
2017 & $40,191.88$ & $42,431.92$ & $47,758.46$ \\
\hline
\end{tabular}

adjustment, the operational losses of children's hospitals further increase; in 2018, their operation deficit is as high as 9.44\% (see Table 5).

The overall trends of the ratio of the balance to the financial revenue among children's hospitals are similar to those among general hospitals. After the adjustment, children's hospitals report even higher losses. Furthermore, the difference between the balance ratio of children's hospitals and that of general hospitals has been increasing. In other words, compared with general hospitals, children's hospitals have greater difficulties in balancing their revenue and costs.

\section{Discussion}

The new round of price adjustment policy gradually eliminates the price addition of medicine and consumable medical materials and raises the prices of healthcare services to properly reflect the high value of medical labor and its technical skill set. The policy provides special support for the healthcare services for children, and the prices of such technical services as doctor consultation, hospitalization, and surgery have risen $15 \%$ from their original price levels.
This latest round of price adjustment policy aims at raising the prices of technical services to properly reflect the high value of medical workers' labor and raising the capacity to provide healthcare services to children. The effects of implementing the price adjustment policy show that the operational pressure on children's hospitals has not reduced, and the policy benefits have not fully materialized.

\section{Analysis of the operation difficulties facing children's hospitals}

We invited some experts on hospital management and price administration for an interview and discussion on the operation situation of children's hospitals. Based on a summary and analysis of the interview results, price adjustment policy, actual operation models of hospitals, and the relevant literature, the operation difficulties of children's hospitals can be analyzed from four aspects: technical development, operating costs, public health policies, and hospital behavior patterns.

Slow progress in the medical technologies for children Most new medical technologies for children are adapted 
from diagnostic and treatment technologies for adults. However, the adaptation process takes three to five years or even longer. Hence, the medical technology development for children always lags behind that for adults.

The research and development of new technologies that are only applicable to children are often more expensive, difficult, and time-consuming than for adults. As a result, medical technologies for children advance slowly. Moreover, the research and development of new technologies require many medical researchers. Due to the high demand for pediatricians and their low supply and the difficulty that adult-specialist doctors have in transitioning to pediatrics, the shortage of technical experts also impedes the research and development on medical technologies for children.

\section{Operating costs are not fully covered under the prevailing pricing system}

The operating costs of children's hospitals are high; although the existing medical service pricing system offers some special exceptions for healthcare services for children, hospitals still find their revenue unable to cover their operational costs fully $(5,6)$. The detailed item-based cost data of a municipal children's hospital in 2018 indicate that $34.4 \%$ of all the medical service items have costs exceeded their prevailing prices; moreover, $20.4 \%$ of the service items have higher variable costs than their prevailing prices.

The fees of some medical service items are unable to cover their underlying costs mainly because the children's hospitals provide many supplementary diagnostic and treatment services. A large proportion of the patients at children's hospitals are children who are unable to control their behavior, so during the treatment, checkup, and testing process, some forms of supplementary treatment by medical workers are often needed. As some supplementary treatments lack corresponding pricing standards, the labor costs of medical workers are not reflected in the bills and compensation.

Furthermore, the utilization rates of special medical equipment at children's hospitals are often low, partially due to the lack of cooperation by the young patients. Another reason is the slow progress in the development of new medical technologies for children. Often, newer medical equipment appears and gradually replaces the older equipment before the latter reaches its period of peak usage, which increases the redundancy, maintenance, and operation costs of hospitals. The low utilization rate of medical equipment also increases the costs of each unit of medical service and exacerbates the operation pressure of hospitals.

\section{The public health policies on women and children change the pattern of child diseases}

Thanks to the continued improvement of healthcare for women and children across China, the implementation and optimization of policies on prenatal screening, congenital disability prevention and treatment, and childhood disease prevention and healthcare, the occurrence rates of congenital disabilities and congenital disease and the proportions of critical, difficult, and complicated diseases are continuously decreasing. For these reasons, the national pattern of children's diseases has undergone some changes. Undoubtedly, the major diseases among children are still infectious ones; the clinical treatment of such diseases mainly rely on medicines. Therefore, the price reform policies have had significant impacts on the operations and business performance of children's hospitals.

\section{Hospital behaviors limiting the policy advantages}

Children's hospitals are characterized as large general sections and small specialized sections; large outpatient clinics and small inpatient departments in their operations. They often rely on a large quantity of outpatient clinical services to cover their various operating costs. The large quantity of outpatient clinical services overloads pediatricians, making them lack the time and energy to improve their expertise and professional skills. In the existing performance-based payment system, the personal income of pediatricians is lower than the average salary of all doctors, demotivating pediatricians to work hard. The above situations constrain the spread and progression of diagnostic and treatment technologies for children's diseases, go against the objectives of the current policy reform policies, and compromise the beneficial effects of the price adjustment policies.

\section{Recommendations for children's hospital development}

To overcome the above difficulties, in their future plans, municipal children's hospitals should position themselves precisely based on social demand and the internal management and external administration situations and improve their operational efficiency and performance.

\section{Precise functional positioning and disease composition optimization}

In the future, municipal children's hospitals should actively 
respond to market demands, optimize the composition of their disease coverage, and use internet technologies to create smart hospitals. The municipal hospitals should concentrate on special departments for difficult and complicated diseases and solve the issues of repeated seeking of treatment by patients. It can do these things by giving precise treatments; reducing useless treatments, examinations, and medicines; and lowering the economic burdens on the patients' families. At the same time, their service contents should be optimized through healthcare networks, and the diagnosis and treatment of common diseases should be diverted to secondary hospitals and community hospitals. Children's hospitals can station doctors in those hospitals to help them improve their expertise and social capacity. At the same time, such measures can also help children's hospitals transfer their own costs and reduce their own operating costs.

\section{Optimizing the performance evaluation system and} improving the technical contents of their services

Medical technology improvement and development are the cornerstones of the development of municipal children's hospitals. The children's hospitals should transition from focusing on quantity expansion to paying more attention to providing high-quality medical services. In the existing performance evaluation system for public hospitals, service quantity and relevant indicators are still among the main criteria, which impedes hospitals' efforts to improve their service quality. Therefore, it is necessary to optimize the hospital performance evaluation indicator system based on the functional expectations put on municipal children's hospitals. The weight of service quantity should be lowered, while the weight of medical technologies should be raised, to encourage children's hospitals to improve the technical contents of their services.

\section{Optimizing the internal business processes and improving resource utilization efficiency}

Municipal hospitals have implemented cost accounting for many years and have a good basis for cost accounting. Based on their cost accounting, children's hospitals are gradually moving toward cost management and are paying more attention to cost efficiency. Based on their cost accounting, municipal children's hospitals can analyze the composition of their costs and their business process, optimize their internal working processes, and reduce low-effect and zeroeffect operations. They should try to constantly increase their resource utilization efficiency, reduce the unit costs of service items, improve the marginal contributions of various medical services, and reduce the economic pressure on their operations.

\section{Actively seeking favorable pricing policies to alleviate the economic pressure on their operations}

The municipal children's hospitals need to provide a high proportion of supplementary treatment services in their operations. They should organize their various services, optimize their service processes, and carry out detailed cost accounting on their supplementary service items. For the service items eligible for fee charges, they should quickly carry out the fee charge application and reporting. For the service items that cannot directly charge fees based on the pricing standards, the children's hospitals should record the services provided and seek favorable pricing policies from the superior price administration authorities, so as to reduce the economic pressure on their operations.

\section{Recommendations on the policy support for children's hospitals}

The public municipal children's hospitals have some inherent weaknesses in their economic performance and undertake the responsibilities of providing some social welfare services. Hence, they need more government support. During the transition and adjustment of public municipal children's hospitals to the new pricing regime, the government needs to provide more support and more favorable policies.

(I) Enhancing the favorable policies by allowing for higher prices for the healthcare services for patients below 6 years old: compared with adult patients, patients below 6 years old require more medical resources from hospitals during their consultation and treatment. Due to the special characteristics and complexity of healthcare services to children, it is recommended that higher prices be allowed for the healthcare services to children, especially the surgeries of serious technical difficulty and risk, and the various checks and examinations requiring supplementary services, such as computed tomography (CT), magnetic resonance imaging (MRI), and blood tests.

(II) Increasing investment in children's hospitals. Compared with other hospitals, children's hospitals have some natural weaknesses. They are less profitable and face high economic pressure in their 
operations. They offer low salaries and struggle to attract excellent medical workers. At the same time, they are unable to timely update their medical equipment to improve their capacity for clinical research. To improve the clinical diagnostic and treatment capacity and the research capacity of children's hospitals, in addition to the efforts by the hospitals themselves, the government needs to increase their financial support to help them successfully through the difficult transition period and achieve a sustainable and healthy future.

\section{Conclusions}

Children are the future of a country; improvement of the pediatric service capacity can support the healthy growth of children (7). The recent price adjustment policies have significantly improved the revenue composition of children's hospitals. However, their insufficient potential to enhance business growth has caused heavy losses and economic difficulties in their operations.

Under the new price adjustment policy, municipal children's hospitals need to actively boost the development of their diagnostic and treatment technologies and shift from quantity-centered to quality-centered development, concentrate their resources on fostering their strong sections and key technologies, and thereby improve the service quality and competitiveness. At the same time, they should help other members of the children's healthcare networks improve their pediatric diagnostic and treatment capacity and work together to provide healthcare support for the healthy growth of children.

In addition, in the transition of children's hospitals to the new pricing regime, the government should enhance its policy support. For one thing, it should improve the pricebased compensation mechanism and increase the prices of the healthcare services for children to more properly reflect the values of pediatric services. For another, it should increase fiscal support for children's healthcare facilities and improve the research, development, and technical capacity of children's hospitals.

Exciting is that output the policy recommendations of this study has been recognized by government departments and adopt, for children under 6 years of age the medical service price compensation policy inclination has been integrated into the next round of reform of medical service prices, increase investment in pediatric type hospital construction Suggestions have also been included in the new children's health service ability construction plan. The new reform exploration deserves our expectation and further discussion.

\section{Acknowledgments}

Funding: This work was supported by grants from Financial Special Fund of Shanghai Municipal (19Y04012). The funders had no role in study design, data collection and analysis, decision to publish, or preparation of the manuscript.

\section{Footnote}

Reporting Checklist: The authors have completed the PRISMA reporting checklist. Available at http://dx.doi. org/10.21037/atm-20-6863

Conflicts of Interest: All authors have completed the ICMJE uniform disclosure form (available at http://dx.doi. org/10.21037/atm-20-6863). The authors have no conflicts of interest to declare.

Ethical Statement: The authors are accountable for all aspects of the work in ensuring that questions related to the accuracy or integrity of any part of the work are appropriately investigated and resolved.

Open Access Statement: This is an Open Access article distributed in accordance with the Creative Commons Attribution-NonCommercial-NoDerivs 4.0 International License (CC BY-NC-ND 4.0), which permits the noncommercial replication and distribution of the article with the strict proviso that no changes or edits are made and the original work is properly cited (including links to both the formal publication through the relevant DOI and the license). See: https://creativecommons.org/licenses/by-nc-nd/4.0/.

\section{References}

1. Wang H, Jin C, Wang W, et al. Development of a price comparison system for Shanghai's medical service pricing. Chinese Journal of Hospital Administration 2015;(8):627-30.

2. Wang M, Wang H, Wang L, et al. Analysis of the Structural Transformation of the Medical Income and Expenditure of Public Hospitals after the Adjustment of Medical Service Prices in Shanghai. Chinese Health 
Economics 2019;38:23-6.

3. Zhang X, Wang H, Zhou J, et al. Analysis of the operating economic status of public hospitals in Shanghai from 2014 to 2016. Chinese Health Resources 2018;21:491-5.

4. Zhao G, Chen W, Zheng Y, et al. Analysis of the Compensation Mechanism of Public TCM Hospitals in Zhejiang Province. Chinese Health Economics 2009;28:69-71.

5. Yang F, Chen D, Luo Z. Discussion on the adjustment

Cite this article as: An Y, Wang M, Wu X, Wang L, Zhang K. Analysis of the economic performance of municipal Children's Hospitals in Shanghai: a study on the impacts of policy changes in healthcare service prices. Ann Transl Med 2020;8(22):1479. doi: 10.21037/atm-20-6863 strategies for medical service prices of public hospitals. China Medical Administration Sciences 2017;7:20-4.

6. Wang Z. Empirical Analysis on the Reasons for Operating Losses of Children's Hospitals. Chinese Health Economics 2017;36:79-81.

7. Gao C, Cui W, Luo S, et al. The present situation and developmental prospect of the medical care of infants and children in Shanghai. Chinese Health Resources 2012;15:459-61. 